\title{
Benchmarking and compliance in the UK Offshore Decommissioning hazardous waste stream
}

Joe Ford ${ }^{1}$, Sean Loughney ${ }^{1}$, Eddie Blanco-Davis ${ }^{1}$, Ava Shahrokhi ${ }^{1}$

${ }^{1}$ School of Engineering, Liverpool John Moores University, Liverpool, United Kingdom. E-mail: j.m.ford@2019.ljmu.ac.uk s.loughney@limu.ac.uk e.e.blancodavis@limu.ac.uka.shahrokhi@limu.ac.uk

June Calder ${ }^{2}$

${ }^{2}$ Health and Safety Executive, Aberdeen, United Kingdom.E-mail: June.Calder@hse.qov.uk

David Ogilvie $^{3}$, Erik MacEachern ${ }^{3}$

${ }^{3}$ Scottish Environment Protection Agency Aberdeen, United Kingdom, E-Mail : david.ogilvie@sepa.org.uk, erikmaceachern@gmail.com

The decommissioning sector of the United Kingdom offshore oil and gas industry is growing rapidly due to the number of ageing installations within United Kingdom waters. In line with current United Kingdom requirements, installations must be decontaminated from hazardous waste before any part can be reused or recycled. This hazardous waste must be handled, transported, and disposed of in a way that does not impact safety or the environment. This research project analyses the key issues associated with the handling of hazardous waste during the decommissioning of offshore installations with the United Kingdom Continental Shelf. A comprehensive literature review and analysis of decommissioning close-out reports was conducted to allow for the key issues to be identified. Expert judgements were sought and analysed using an analytical hierarchy process. This study emphases the need to improve the handling of hazardous materials during the decommissioning process. The clarity of legislative requirements, identification of hazardous materials and sharing of knowledge and experience are areas that require improvement to meet the increasingly stringent environmental and sustainability requirements.

Keywords: Offshore Decommissioning, Waste Management, Legislation, Analytical Hierarchy Process, UKCS.

\section{Introduction}

Following the introduction of the UK Continental Shelf Act in 1964, several oil and gas field developments have taken place within the UKCS. There are currently 470 active offshore installations in UK waters (SEPA, 2018). Many of these are fixed steel installations that have a typical design life of 20 years. As an installation reaches the end of its design life, a decision must be made as to whether to carry out a late-life extension or to decommission it. With the current move towards a circular economy (Milios et al., 2019) ways to decommission an installation safely and sustainably need to be developed.

Part of the decommissioning process must address how to handle the hazardous waste materials from the installation. These hazardous materials must be identified, handled, transported, and processed in line with current legislation. As many installations have exceeded their 20year design life by this point, often they have undergone changes in operators, crew and operating phase and seen changes in regulations and legislation. These changes can cause loss of information with regards to equipment and materials onboard. When information is missing, hazardous materials may be present in unknown volumes and composition which has the potential to result in accidental release causing injury or environmental damage.

To increase the sustainability of the decommissioning process, the volume of waste that is reused or recycled must be maximised. Many new offshore installations are being designed with decommissioning activities considered as part of a life cycle assessment. Older, existing installations were not designed with the same consideration and hence, can pose more of challenge.

\subsection{Aims and objectives.}

The aim of this research project is to identify the key issues with regards to the sustainable management of hazardous materials prior, during and after recycling following the decommissioning of an offshore installation.

The research objectives of this project are:

(i) To identify and discuss the legislation and requirements for hazardous waste associated with offshore installations.

(ii) To identify and analyse the key issues with regards to the sustainable management of hazardous materials.

(iii) To explain the required control, enforcement, and waste infrastructure for the decommissioning stage of an offshore installation.

\section{Literature Review}

In 2015 all United Nation (UN) Member States adopted the UN 2030 Agenda and its 17 sustainable goals (UN, 2015). Goal number 12 addresses responsible consumption and production, particularly of raw materials, whilst goal 13 highlights climate action and the move to reduce greenhouse gas emissions. Due to the current focus on sustainability and climate change, the environmental impact from the entire life cycle of an offshore installation must be minimised.

There are currently 470 offshore installations in UK waters, along with their associated subsea equipment and pipelines (SEPA, 2018). Two hundred thirty of those are 
estimated to have to undergo decommissioning activity between 2019 - 2028 (OGUK, 2019). The Convention for the Protection of the Marine Environment of the NorthEast Atlantic (OSPAR) requires the removal of all installations, including the wellheads and Christmas Trees (OSPAR, 2010). A decommissioning plan must be submitted to and approved by the Offshore Petroleum Regulator for Environment and Decommissioning (OPRED) (OGUK, 2015). In 2018, 120,000 tonnes of waste was processed from decommissioned installations (OGUK, 2019) but it is estimated that this will increase by $39 \%$ in the next year. Hence the importance of ensuring the waste is handled correctly, reused or recycled where possible. $20 \%$ of overall installations will be decommissioned over the next ten- year period (OGUK, 2019) along with $20 \%$ of wells and $25 \%$ of pipeline infrastructure.

\subsection{Decomissioning Waste Materials}

Part of the decommissioning process is to identify the waste and categorise it according to the European Union (EU) Waste Hierarchy (EU, 2008). From this, an active waste management plan can be formulated. Waste is defined as "any substance or object which the holder discards or intends, or is required to discard" by the EU Waste Framework Directive (EU, 2008). The waste from offshore installations ranges from asbestos to equipment contaminated with naturally occurring radioactive material (NORM). Typical examples of hazardous waste are trapped gas or hydrocarbons, asbestos, residual diesel and oils, drill cuttings, mercury, and NORM.

\subsection{Sustainability}

Engelseth (2016) highlights that waste should be referred to as "a resource" to ensure that it is valued, to create clearer supply chain management initiatives and not to be viewed as something that is simply going to be disposed of. Engelseth (2017) goes on to suggest that waste management be viewed as a "reverse supply chain".

Zhang et al. (2019) assessed the current maintenance strategies of offshore installations using data mining to propose suitable strategies. De Almeida, et al. (2017) assessed waste management in offshore oil and gas processes through the analysis of environmental, economic, safety and technical aspects. They used decision making processes to suggest improvements to sustainability. Response to the Deep-Water Horizon accident led to a re-examination of asset maintenance and safety managements (Sweeten, 2012).

\subsection{Safety}

Robinson and Cowie (2003) highlighted the importance of the duty of care with regards to the transportation of hazardous waste. This duty of care flows across the entire waste chain but is dependent on the awareness, planning, and management strategies of the hazardous waste. It is influenced by the correct identification of the waste and correct disposal procedures.

\section{$2.4 \quad$ Roles and Responsibilities}

Calder (2019) outlined the HSE's role in the decommissioning process. She highlighted the importance of the safety case revisions and the changing of the risk profile during the decommissioning process. Once an installation, or its parts, are brought onshore for dismantling, it is no longer under the permissioning regime, but an inspection led one. Operators must have a clear understanding of their legal roles and responsibilities. Calder (2019) also highlighted that when an installation is being transported to an onshore yard, it is no longer under HSE until it reaches shore. These issues had previously been raised by Parente et al. (2006), who highlighted the difficulty in the tracking of responsibilities as the project changed hands.

Adetoro (2009) also stated that identifying obligations and liability are a concern. OGUK (2008) discussed the lack of and limited disposal routes for installations and the loss of as-built information due to changes in staffing. Ahiaga-Dagbui et al. (2017) state that many installations built prior to 1998 OSPAR "were not designed with decommissioning in mind". The information available about the installation exists in different formats, and there is often limited budget for inspection, surveys and familiarisation visits. Walker and Roberts (2013) also raised a similar issue stating the lack of knowledge sharing, trust issues and a skills deficiency.

\subsection{UK Statutory Regime}

The current statutory regime in the UK is designed to meet the international obligations including OSPAR, UNCLOS and the Geneva Convention. UK legislation sets out how these will be met. Regulatory bodies enforce these legislations and issue guidance on how they can be met. Fig. 1 shows a general overview of their hierarchy.

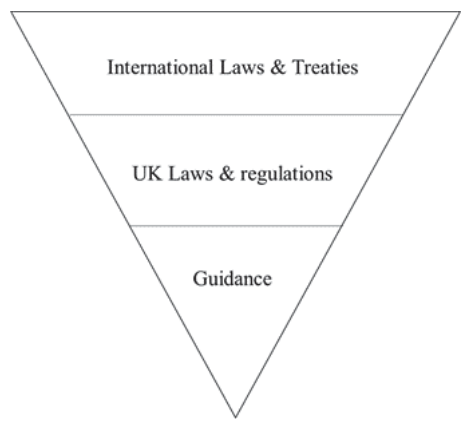

Fig. 1: Hierarchy of laws.

Lindøe, et al. (2013) discusses the robustness of the UK regulatory regime in comparison with the US and Norwegian sectors. They highlight how change in legislation is accident driven and that although UK legislation is a benchmark, it lags behind the Norwegian sector. Hale (2014) states that the Norwegian scheme is the most explicit and articulated. Engen and Lindøe (2019) question the goal setting approach of UK legislation, stating that companies and operators must justify their decisions to the regulatory bodies for approval. This requires a high level of understanding of the legislation. 
Calder (2019) states that one of the key issues with the legislation surrounding the offshore industry, and in particular, decommissioning is the boundary between offshore and onshore. Operators must also be clear on when an installation ceases to be classed as operating under offshore legislation and switches to marine regulations. SEPA (2019) also highlight the issue of boundaries and areas of jurisdiction. Fig. 2 shows a simple overview of areas that each authority and agency operate. The limit for onshore waste regulations extends only to the low water line.

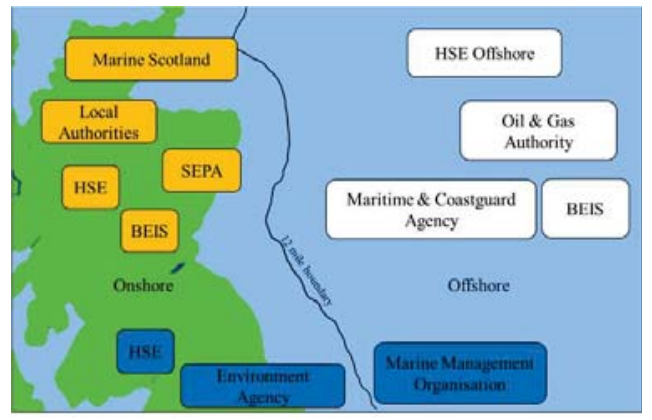

Fig. 2: Areas of Jurisdiction of Regulatory Bodies and Authorities (based on SEPA (2018)).

Calder (2019) highlights that operators must recognise all activities associated with decommissioning include work undertaken by other vessels such as support vessels. Onshore activities do not follow the same permissioning scheme as the offshore activities. Contractors, waste handlers, dismantlers and recycling companies must already be registered with relevant body and be licensed to handle specific waste products. It is the operator's duty of care to audit any onshore work to ensure that this is the case. Throughout this process of identification to disposal, it must be clearly identified, tracked, and handled correctly. There is a possibility that it may get lost or not processed by the correct operators.

\section{Methodology}

Thiel (2014) states that "engineering research is based on the principles of scientific research where observations, theories, calculations and models are derived from existing bodies of scientific knowledge." Research questions arise from identifying gaps in current literature through a critical review (Greenfield and Greener, 2016). The choice of methodology is determined by the research question, aims and objectives. The research methodology is the philosophy or general principles which guide the research whilst the method is the tools to gather the data (Dawson, 2009). Qualitative research is based on exploring articles, behaviours and experiences whilst quantitative research is based around data and statistics (Dawson, 2009). This research project will follow an inductive, quantitative approach as it will be data-driven to allow for a theoretical explanation to be developed (Saunders, Lewis and Thornhill, 2012). A deductive approach has not been selected as a theory is not being tested.

AHP has been shown by França et al. (2020) that it can be used as part of a decision-making process. They used AHP to identify key issues of a risk assessment process. AHP has the advantage of being flexible and able to be applied to a wide variety of problems. Oguztimur (2011) outlines some of the advantages and disadvantages of using AHP. The key advantage is that AHP relies on the judgements of experts so allows for the problem to be evaluated easily and for priorities to be identified but this can also be viewed as a disadvantage. The model must be designed within a boundary that allows the alternatives to be identified. If a new alternative is identified, the model must be adjusted to include this. This increases the amount of computation required as the size of the model increases.

\subsection{Research Framework}

In order to ensure the success of this research project, a clear framework was required. The proposed framework was based on the Health and Safety Executive Risk Assessment framework (HSE, 2006). This framework was designed to be used in conjunction with the offshore Safety Case Regulations by asset managers, safety managers and safety engineers. It provides guidance for identifying hazards which are akin to the key issues being sought for this project. Fig. 3 shows the proposed framework for this project.

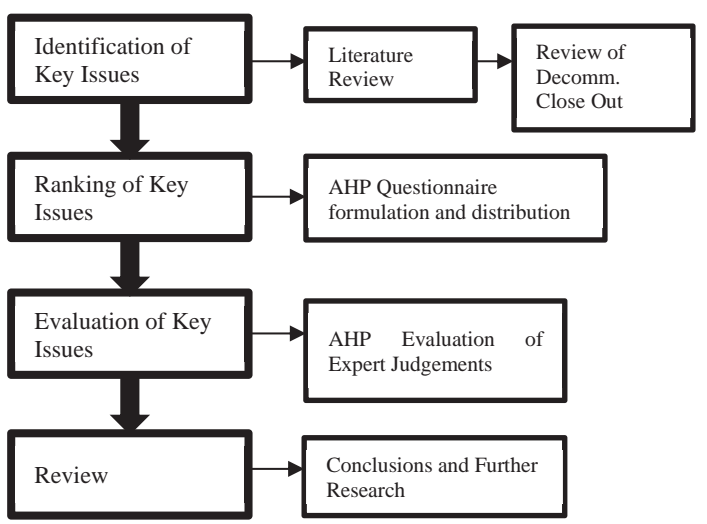

Fig. 3: Proposed research framework.

The initial stage in the research involved a comprehensive literature review that is shown in Chapter 2. Through the analysis of the available literature, several key issues have been identified. Together with a review of publicly available close-out reports, several key issues were identified to be focused on and used to carry out an analytical hierarchy process. This second stage enabled a questionnaire to be produced based on an initial Bayesian network. This questionnaire was distributed to experts identified with the offshore decommissioning sector. The results of these questionnaires allowed for the identification of potential key issues in the 
Decomissioning Waste Management stream. Finally, a conclusion could be reached and suggestions for further research made.

\subsection{Overview of Analytical Hierarchy Process}

The AHP approach is a structured technique for organising and analysing complex decisions. It is based on the well-defined mathematical structure of consistent matrices and their associated right eigenvector's ability to generate true or approximate weights. It enables the comparison of criteria with respect to a benchmark in a similar fashion to the pair-wise comparison mode. Such a comparison uses a fundamental scale of absolute numbers.

The first step in the AHP process is to define the problem and identify the goals or objective. This enables a hierarchal structure to be developed from the top goal to sub-criteria to alternatives. The hierarchal structure is shown in Fig. 5.

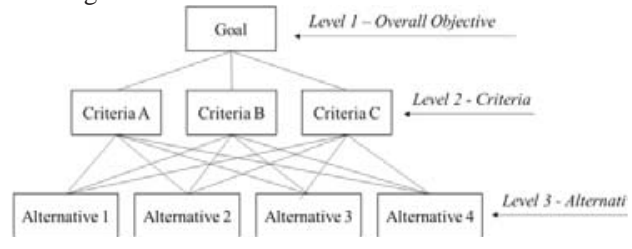

Fig. 5: Example of the hierarchal structure

Once the hierarchy has been determined, a questionnaire can be developed to allow for each alternative and criteria to be compared. A questionnaire is developed to allow the comparison of the alternatives. The results of the questionnaire enable a pairwise comparison matrix to be produced.

The questionnaire requires the respondent to compare alternatives and to rank their importance using the Saaty Scale. For example, in this analysis the scale is as follows: " 1 is equal importance", " 3 is moderate importance", " 5 is strong importance", "7 is very strong importance", "9 is extreme importance" and " $2,4,6$, and 8 are intermediate values of importance". This fundamental scale has been shown to be a scale that captures individual preferences with respect to quantitative and qualitative attributes (Loughney, 2017).

A set of questionnaires, applying the fundamental scale for absolute numbers, was sent to selected experts in the offshore industry for their evaluation. The feedback is investigated according to their judgements on the criteria under discussion. This feedback, in the form of a pairwise comparison, is utilised to determine the relative weights of the parent nodes using AHP. The backgrounds of the experts, who shall remain anonymous, is as follows:

- Expert 1: 5-years' experience with the decommissioning sector specialising in piping and pressure vessels. Holds Master's degree.

- Expert 2: More than 10 years' experience with the decommissioning sector. Holds Master's degree.

- Expert 3: More than 10 years' experience with the decommissioning sector specialising in verification and audits. Holds Master's Degree and chartered status.

- Expert 4: More than 10 years' experience with the decommissioning sector specialising in environmental issues. Holds PhD.

- Expert 5: 8-years' experience with the decommissioning sector specialising in subsea wells. Holds Bachelor's Degree.

- Expert 6: 8-years' experience with the decommissioning sector. Holds Master's degree.

To identify the importance of each criterion, in relation to the alternatives, an AHP approach containing a pair-wise comparison matrix will be used. To conduct the pairwise comparison matrix, at first, set up $n$ criteria in the row and column of an $n \times n$ matrix.

The judgements on pairs of attributes $A_{i}$ and $A_{j}$ are represented by an $n \times n$ matrix A as shown in Eq. (1)

$$
A=\left(a_{i j}\right)=\left[\begin{array}{cccc}
1 & a_{12} & \ldots & a_{1 n} \\
a / a_{12} & 1 & \ldots & a_{2 n} \\
1 / a_{1 n} & 1 / a_{2 n} & \ldots & 1
\end{array}\right]
$$

where $i, j=1,2,3, \ldots, n$ and each $a_{i j}$ is the relative importance of attribute Ai to attribute $A_{j}$.

For a matrix of order $n,(n \times(n-1) / 2)$ comparisons are required. According to Ahmed et al. (2005), each element in the pair-wise comparison matrix carries a weight vector which indicates their priority in terms of its overall contribution to the decision-making process. These weight values are found using Eq. (2).

$$
w_{k}=\frac{1}{n} \sum_{j=1}^{n}\left(\frac{a_{k j}}{\sum_{i=1}^{n} a_{i j}}\right)(k=1,2,3, \ldots, n)
$$

where $a_{i j}$ is the entry of row $i$ and column $j$ in the comparison matrix of order $n$.

The weight values obtained in the pair-wise comparison matrix are checked for consistency purpose using a Consistency Ratio (CR). The CR value is computed using the following equations:

$$
\begin{gathered}
\lambda_{\max }=\frac{\sum_{j=1}^{n} \frac{\sum_{k=1}^{n} w_{k} a_{j k}}{w_{j}}}{n} \\
C R=C I / R I \\
C I=\frac{\lambda_{\max }-n}{n-1} \\
C R=C I / R I
\end{gathered}
$$

where $\mathrm{n}$ equals the number of items being compared, $\lambda_{\max }$ stands for maximum weight value of the $\mathrm{n} \times n$ comparison matrix, RI stands for average random index (Table 1) and CI stands for consistency index. 
$\mathrm{CR}$ is designed so that a value greater than 0.10 illustrates an inconsistency in the pairwise comparison. If the CR is 0.10 or less, then the pair-wise comparison is considered consistent and reasonable. Should the inconsistency level in the pairwise comparison be unacceptably high, a revisit to the expert judgements would be required. It is also possible to approach more domain experts in the elicitation process.

Table 1: Random consistency index (Saaty and Kearns, 1985)

\begin{tabular}{l|lllllllll}
\hline $\mathrm{n}$ & 2 & 3 & 4 & 5 & 6 & 7 & 8 & 9 & 10
\end{tabular}

\begin{tabular}{llllllllll} 
RI & 0.00 & 0.58 & 0.90 & 1.12 & 1.24 & 1.32 & 1.41 & 1.45 & 1.49 \\
\hline
\end{tabular}

The consistency ratio must be less than $10 \%$. Saaty and Kearns (1985) suggests that in some cases, 20\% may be tolerated. If the consistency ration is exceeded, then the experts must revise their judgements. The final priority matrix for each expert can be produced by finding the sum of the products of the weight for each criterion and weight for each alternative.

$$
\begin{aligned}
& \text { Final priority for Each Altenative } \\
& \qquad=\sum_{i=1}^{n} W_{i j} W_{\text {criteria } i}
\end{aligned}
$$

When there are multiple expert respondents, an aggregated response is required. A procedure is only considered satisfactory if it:

i. Reflects the collective judgements of the respondents.

ii. Responds to changes in individual preferences.

iii. Provides ranking for the alternatives presented (Saaty and Vargas, 2013).

If none of the respondent's opinions are considered greater than the others, then an aggregated response can be found using the geometric mean of the weights (Saaty and Vargas, 2013). The geometric mean method is also advocated by Liberatore and Nydick (2003) when a consensus cannot be made through discussion.

$$
W^{G}=\left(\prod_{i=1}^{n} W_{i}\right)^{1 / n}=\sqrt[n]{W_{1} W_{2} W_{3} \ldots \ldots \ldots W_{n}}
$$

\section{Data Gathering and Results}

The decommissioning process requires the identification, handling and processing of waste materials in order to maximise the volume of recyclable and reusable material. Where hazardous materials are present, they must be handled and processed in line with current regulations and legislation to prevent accidental release, injury or environmental damage. A comprehensive literature review and AHP analysis have been conducted to determine the key issues associated with handling hazardous waste.

\subsection{Identification of Key Issues}

Through review of current literature, detailed in Section 2, the key issues identified for the handling of hazardous waste during the decommissioning process were:

i. Identification of waste materials

ii. Traceability and liability whilst handling waste

iii. Total volume of material recycled or reused

iv. Understanding and application of the current regulations and legislation.

v. Quality of surveying and testing prior to decommissioning.

Following the review of the close-out reports, the following issues were identified:

i. Actual volume of hazardous waste compared with predicted volume.

ii. Thoroughness of cleaning and decontamination

iii. Traceability of materials.

By using the top-down approach, the relationships between these key issues and the hazards were determined. This was then used to create a sequence of event and a corresponding AHP hierarchy structure.

For this research project, the improper handling of waste will be defined as any handling that results in accidental release or discharge of hazardous materials, loss of hazardous material, injury or death. The release of hazardous materials can also result from external events such as:

i. Environmental - extreme weather and sea conditions.

ii. Transportation - liked to the vessel transporting the waste such as collisions, contacts, capsizing, loss of hull integrity and berthing events.

iii. Fire and explosion - resulting from equipment failure.

As these issues are not specific to the handling of waste alone, they will not be considered. Their inclusion would also increase the volume of data required to be collected and analysed. This is beyond the time scale of the project. Only the key issues identified from the literature review are included in the analysis.

To allow for the interactions between the key issues to be determined, a brainstorming process was used alongside a simple bowtie diagram. Brainstorming allows for ideas and issues for a specified problem to be generated through tapping into creative thinking (Wang and Trbojevic, 2007). A bowtie diagram represents how a hazard is released and the potential consequences. Typically, the causes are represented using fault tree analysis and the consequences through event tree analysis (Wang and Trbojevic, 2007). Barriers to the threats are normally represented but were not included in order to simplify the process and focus on the hazards. A simple combination of brainstorming and bowtie diagram were used to identify the causes and consequences. The consequences of improper handling can be split into the following groups:

i. Environmental events

ii. Liability events 
iii. Injury or death

iv. Volume of materials recycled or reused.

Using the identified consequences, a simple events tree was determined to aid in identifying how the causes and consequences interacted. The event tree is shown in Fig. 6.

Following the method outlined in Section 3, a hierarchy structure was created. The resulting AHP hierarchy structure is shown in Fig. 7.

Each criteria and level were based on the key issues identified in Section 2. They are presented as summarised statements in Fig. 7 for clarity. The explanation of each level in the hierarchy structure is listed below:

- Goal: Improper handling of hazardous waste -any handling that results in accidental release or discharge of hazardous materials, loss of hazardous material, injury or death.

- Criteria 1: Understanding of current legislation understanding of obligations and duty of care for current legislation for the decommissioning of offshore installations with a focus on hazardous waste materials.

- Criteria 2: Total percentage of material recycled or reused. -the volume (percentage) of material recycled and reused from the decommissioning process due to accurate identification and handling of hazardous waste materials.

- Criteria 3: Identification of hazardous material - the correct identification of hazardous materials present in accordance with EU waste framework and REACH guidelines.

- Alternative 1: Knowledge of legislation - knowledge of current legislative requirements for handline and processing of hazardous waste materials during decommissioning activities.

- $\quad$ Alternative 2: Hazardous materials surveys - surveys and testing carried out to identify types of and volumes of hazardous materials present prior to cleaning and decontamination commences

- Alternative 3: Traceability of hazardous materials understanding and implementation of duty of care for traceability of hazardous materials throughout the entire decommissioning process.

- Alternative 4: Prior experience with hazardous materials - operators and contractors prior experience with handling and processing hazardous materials typically found on offshore installations.

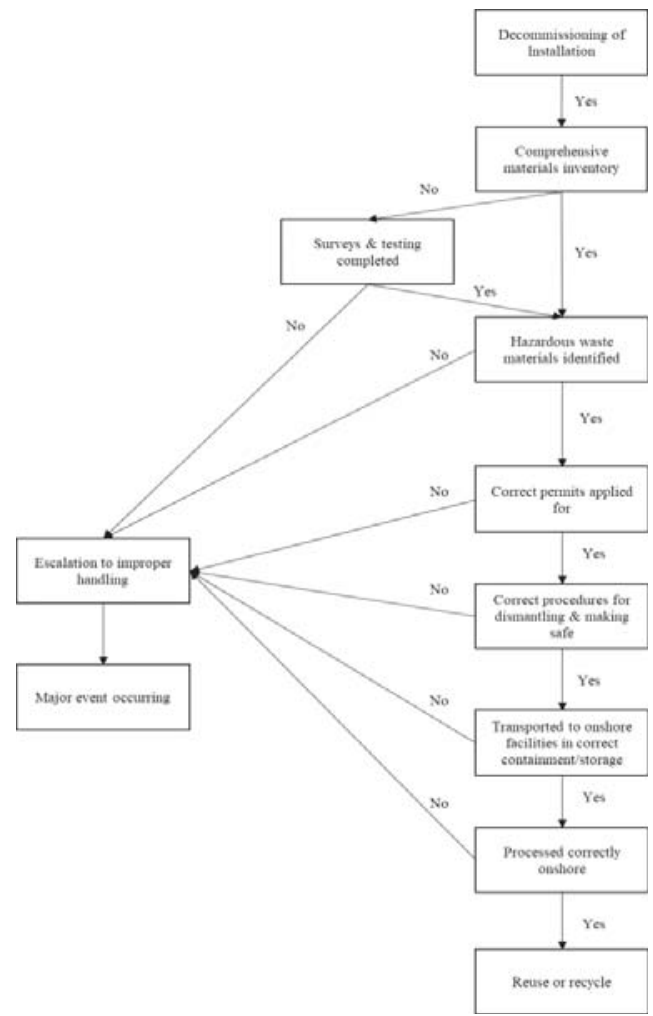

Fig. 6: Event tree for handling hazardous waste.

\subsection{Pairwise Comparison}

The responses to the questionnaire allowed for pairwise comparison matrices to be produced.

Table 2 shows the abbreviated criteria used through the analysis to allow for clarity. Table 3 shows an example of an individual experts' judgements when presented as pairwise comparison matrix.

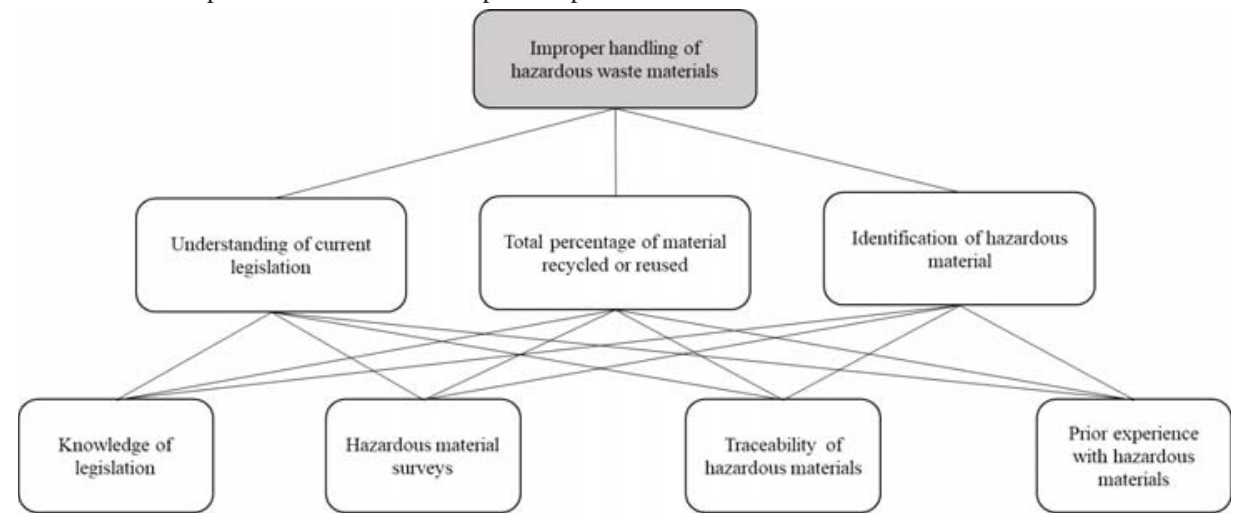

Fig. 7: Hierarchy structure using identified key issues. 
Table 2: Criteria required for comparison at level 1.

\begin{tabular}{cc}
\hline Criteria - Level 1 \\
\hline Understanding of current legislation & C1 \\
Total percentage of material recycled or reused & C2 \\
Identification of hazardous material & C3 \\
\hline
\end{tabular}

Table 3: Pairwise comparison matrix for level 1 criteria

\begin{tabular}{l|lll}
\hline & C1 & C2 & C3 \\
\hline C1 & 1 & 2 & 0.17 \\
C2 & 0.50 & 1 & 0.14 \\
C3 & 6 & 7 & 1 \\
SUM & $\mathbf{7 . 5 0}$ & $\mathbf{1 0}$ & $\mathbf{1 . 3 1}$ \\
\hline
\end{tabular}

Using Table 3, a standardised matrix could be created. The ranking in each cell of Table 3: 3 are divided by the sum of their column. If the standardisation is correct, the sum of the columns equal 1 (Saaty and Kearns, 1985). The standardised matrix is shown in Table 4.

The consistency ratio is calculated to determine the consistency of the expert's judgements. Each column in Table 3 is multiplied by their weight in Table 4 to produce Table 5. The sum weighting is the sum of the rows in Table 5 divided by the weight in Table 4 .

Table 4: Normalised comparison matrix for level 1 criteria

\begin{tabular}{lllll}
\hline & C1 & C2 & C3 & Weight \\
\hline C1 & 0.13 & 0.20 & 0.13 & 0.15 \\
C2 & 0.07 & 0.10 & 0.11 & 0.09 \\
C3 & 0.80 & 0.70 & 0.76 & 0.75 \\
\hline SUM & 1.00 & 1.00 & 1.00 & 1.00 \\
\hline
\end{tabular}

Table 5: Sum row and sum weights to be used for calculating consistency index.

\begin{tabular}{llllll}
\multicolumn{6}{c}{ calculating consistency index. } \\
\hline 1 & 0.15 & 0.18 & 0.13 & 0.46 & 3.02 \\
2 & 0.08 & 0.09 & 0.11 & 0.28 & 3.01 \\
3 & 0.92 & 0.64 & 0.75 & 2.32 & 3.07 \\
\hline
\end{tabular}

Using Eq. (3) , the maximum eigenvector can be determined.

$$
\lambda_{\max }=\frac{3.02+3.01+3.07}{3}=3.03
$$

This allows for the consistency index to be calculated using Eq. (4).

$$
C I=\frac{3.03-3}{3-1}=0.016
$$

The consistency ratio is calculated using the random index shown in Table 2 and Eq. (5).

$$
C R=\frac{0.016}{0.58}=0.029
$$

The consistency ratio must be less than 0.1 for the judgements to be viable. If the consistency index is below 0.1 , then the individual weights would have been aggregated using the geometric mean method outlined in Section 3.

The final priority matrix, Table 6 was generated by combining the individual weights for each alternative and criteria using Eq. (7).

Table 6: Overall priorities for each alternative.

\begin{tabular}{l|lll|l}
\hline Synthesis & C1 & C2 & C3 & Overall Priorities \\
\hline A1 & 0.09 & 0.12 & 0.09 & $\mathbf{8 . 8 8 \%}$ \\
A2 & 0.25 & 0.25 & 0.25 & $\mathbf{2 5 . 4 \%}$ \\
A3 & 0.25 & 0.25 & 0.25 & $\mathbf{2 5 . 4 \%}$ \\
A4 & 0.40 & 0.39 & 0.40 & $\mathbf{4 0 . 3 \%}$ \\
\hline
\end{tabular}

\section{Discussion and Conclusions}

The priority matrix shown in Table 6 indicates that the alternative A4 has the highest ranking and A1 has the lowest. This demonstrates that Alternative 1 is the lowest priority in terms of the assessment. This could potential be of concern to operators and regulators throughout the UK Offshore Decomissioning Waste Stream as there is a very low opinion of importance related to the Knowledge of legislation. Furthermore, this is true across each comparison of A1 with the 3 criteria (C, C2 \& C3). This reinforces the claims made by Calder (2019), the one of the key issues is with the legislation surrounding the offshore industry and the waste stream. Similarly, SEPA (2019) also highlight the issue of boundaries and areas of jurisdiction, this is a potential reason for the perceived lack of importance of Knowledge of Legislation.

The offshore industry is regulated by several international, national, and regional agencies. The Oil \& Gas Authority regulates the industry in order to maximise the economic recovery of the UK's oil and gas reserves based on the MER strategy. The Health and Safety Executive is responsible for regulating the risks to health and safety. Waste is regulated by the Scottish Environmental Protection Agency and the Environment Agency.

There are several different regulations and legislations that govern the handling of the waste. One of the key issues that arose was the transfer of waste from the installation to the onshore site. The regulations depend on the location of the waste, on the installation, on a vessel or onshore. The transfer of waste between contractors and handlers also presents a problem with traceability. Ultimately, the installation operator has a duty of care to ensure that the waste is handled appropriately. The knowledge and understanding of the legislations are key as well as a robust active waste management plan being in place. The AHP analysis identified that knowledge of legislation is a potential issue when managing the offshore decom waste stream.

The close-out reports available from the BEIS highlighted that the quality of surveys, decontamination and cleaning of equipment prior to its removal was a key issue. The predicted volumes of hazardous waste were often found to be less than actual volumes present, and the inadequate decontamination meant that equipment was transported still containing hazardous materials. 